\title{
Patrimônio cultural e turismo: relações entre oferta, geração de empregos e sustentabilidade
}

\author{
Giancarlo Moser ${ }^{1}$
}

\section{RESUMO}

Este artigo explora o potencial do turismo para impactar positivamente na criação de empregos, especialmente sua capacidade de estimular outros setores da economia, especificamente à proposta de uso do Patrimônio Histórico para demonstrar como as pessoas, especialmente das comunidades desfavorecidas, podem participar e se beneficiar da indústria do turismo. $\mathrm{O}$ turismo desponta hodiernamente como uma das principais opções adotadas para a dinamização dos espaços do patrimônio histórico e cultural, selecionando, adaptando e comercializando os espaços das áreas urbanas, patrimonializados e utilizados enquanto espaços turísticos, para visitação e contato com a história e a cultura das cidades bem como contribui para o debate teórico e prático para políticas de gestão do patrimônio cultural urbano, para a elaboração de alternativas de modelos de desenvolvimento do turismo e de apropriação desses patrimônios. Os debates e as questões relacionadas ao Patrimônio Histórico e Cultural vêm introduzindo uma nova realidade e causando diferentes impactos na oferta da atividade turística. O consumo do patrimônio e a mercantilização da cultura, em sentido lato e numa acepção antropológica, ampla e científica, trouxeram uma nova dinâmica ao setor, pelo crescente desejo de se conhecer e compreender aqueles que são os recursos específicos dos destinos turísticos, com a possibilidade de serem transformados em vantagens competitivas.

Palavras-chave: Patrimônio Cultural; Turismo e Emprego; Patrimônio e Turismo; Turismo Cultural

\section{INTRODUÇÃO}

O Conselho Mundial de Viagens e Turismo (WTTC, 2015) diz que "a indústria de viagens e turismo, incluindo serviços diretos como hotelaria e gastronomia, emprega um a cada dez trabalhadores no mundo", que se traduziu numericamente, em 2015, em 108 milhões de vagas diretas, em um total de 292 milhões entre diretas e indiretas no mundo inteiro. Somente no Brasil, o setor impacta R \$ 520 bilhões na economia e é responsável pelo sustento direto de mais de sete milhões de brasileiros, segundo a Embratur (2016).

A experiência internacional pode ser utilizada também para demonstrar que o turismo representa cerca de um décimo do mercado de trabalho em Espanha, representando 686.000 empregos diretos e 487.000 indiretos. Além disso, a WTTC (2015) confirma que o turismo é um importante gerador de emprego na Suécia, onde é responsável por cerca de 200.000 empregos a tempo inteiro ou a tempo parcial. Na Colômbia, 360.000 pessoas trabalham no setor hoteleiro e de gastronomia e em alguns países do Caribe, $50 \%$ da força de trabalho está empregada no setor de turismo.

\footnotetext{
${ }^{1}$ Doutor em Ciências Sociais, Mestre em Turismo e Graduado em História e Processos Gerenciais. Professor FVG e UDESC. Email: giancarlo.moser@unesc.net
} 
Portanto, para o turismo gerar um número substancial de empregos, dependerá parcialmente da intensidade do fator de produção das atividades particulares empreendidas. Há uma forte experiência internacional para apoiar essa visão. A Europa, por exemplo, é o destino turístico mais popular do mundo e seu sucesso é construído sobre o turismo cultural. O turismo cultural dificilmente é novo e as pessoas vão à Europa para experimentar a língua, cultura, culinária e ver a arquitetura e os locais históricos, visitar museus e galerias de arte, para participar de eventos culturais e festivais de vários tipos

\section{AS INTERFACES ENTRE O PATRIMÔNIO CULTURAL E A ATIVIDADE TURÍSTICA}

Os debates e as questões relacionadas ao Patrimônio Histórico e Cultural vêm introduzindo uma nova realidade e causando diferentes impactos na oferta da atividade turística no Brasil. O consumo do patrimônio e a mercantilização da cultura, em sentido lato e numa acepção antropológica, ampla e científica, trouxeram uma nova dinâmica ao setor, pelo crescente desejo de se conhecer e compreender aqueles que são os recursos específicos dos destinos turísticos, com a possibilidade de serem transformados em vantagens competitivas.

Nessa perspectiva e na perspectiva da formação de uma economia de mercado globalizada e altamente concorrencial, a promoção do destino deve se conceber sustentada nas características do patrimônio cultural, pois, sendo o turismo um setor dinâmico, os destinos devem continuadamente renovar-se e requalificar-se. Em consequência, emergem em alguns casos novos elementos de oferta turística que promovem alterações no marketing dos lugares e daí, naturalmente, surjam segmentos distintos de produtos turísticos.

\subsection{O Turismo Cultural no contexto}

Em um contexto de turismo cultural, que já não abarca somente os produtos culturais do passado, percebe-se que os responsáveis do setor público e privado sugerem o desenvolvimento da promoção do destino com base em produtos diversos, como: o patrimônio monumental e arquitetônico, os núcleos museológicos, os centros históricos e o artesanato, como forma de captar novos públicos e dar mais visibilidade à cultura regional, que, nesse sentido, Beni (2008, p.473) define que o Turismo Cultural 
Refere-se à afluência de turistas a núcleos receptores que oferecem como produto essencial o legado histórico do homem em distintas épocas, representado a partir do patrimônio e do acervo cultural, encontrado nas ruínas, nos monumentos, nos museus e nas obras de arte.

Por estas razões, é com naturalidade que se encara a valorização do patrimônio regional de interesse turístico como uma vantagem competitiva da oferta turística e da promoção do destino, capazes de contribuir para a renovação da imagem, para uma melhor qualificação dos produtos, para uma mais elevada qualidade dos serviços e para a diversificação de mercados e conseqüente cristalização da procura turística gerando empregos novos para atender as prováveis demandas que afluirão deste processo, mesmo considerando-se que, como alertam Brusadin e Silva (2011).

Um dos grandes paradoxos do turismo cultural é a dificuldade encontrada na gestão do patrimônio cultural, devido principalmente aos conflitos existentes entre os interesses da comunidade local e dos turistas. Logo, para que haja a manutenção da identidade da cultura local é inquestionável que tem de se definir um ponto de equilíbrio do uso turístico para que, assim, se torne possível aproveitar as representações do passado sem deteriorar a memória das comunidades receptoras.

A diversidade do patrimônio cultural herdado e o dinamismo da criação artística cultural, assim como a preservação do patrimônio e a qualidade da oferta cultural, na sua globalidade, concorrem para o poder de atração das localidades. Cultura e turismo estão intimamente ligados na definição das políticas econômicas das regiões, com a atividade cultural a ter um importante papel no fomento da coesão social e do emprego e a afirmar-se como determinante do investimento e como fonte de receitas.

\subsection{A Cultura em seu contexto}

A necessidade de conceituar cultura é imprescindível na tentativa de propor uma política de gestão de bens culturais ou patrimoniais históricos para sua aplicação como oferta turística. Não se trata apenas de definir se o objeto ou os objetos culturais possuem atrativos que possam apresentá-los como uma possível oferta, mas sim, de apresentar uma política de gestão que possa ao mesmo tempo elaborar estratégias competentes para a viabilização dos bens e patrimônios culturais e, posteriormente, atrelar a sua conservação e aplicabilidade como oferta e atrativo turístico, neste caminho Beni $(1998$, p.86) diz "que o turismo é, em certo sentido, o instrumento que serve de veículo à reabilitação das culturas, contribuindo em grande medida para sua difusão mundial". 


\subsubsection{Conceitos e Usos de Cultura}

Na busca de uma conceituação de cultura, partimos pela elaborada pelo antropólogo Clifford Geertz, para quem a cultura compõe um sistema entrelaçado de símbolos compartilhados pelos atores sociais, por meio dos quais eles se comunicam, desenvolvem seu conhecimento e encontram sentindo nos acontecimentos e nas atividades em relação à vida.

Seguindo a sua interpretação, a cultura compõe a dinâmica entre o ethos de um povo e sua visão de mundo, representado uma relação circular entre os elementos valorativos de uma cultura - como seus aspectos morais e estéticos - e os aspectos cognitivos e existenciais. Segundo a definição de Geertz, o ethos de um povo é compreendido como sendo "o tom, o caráter e a qualidade da sua vida, seu estilo moral e estético e sua disposição" (GEERTZ 1989, p. 143) é atitude subjacente em relação a ele mesmo e ao seu mundo que a vida reflete.

A cultura é, portanto, o contexto no qual ocorrem os acontecimentos sociais, transmite-se comportamentos, constroem-se conhecimentos e se configuram instituições. É dentro desse contexto que as pessoas interagem, convivem e compartilham significados, dentro de uma noção análoga à perspectiva do habitus ${ }^{2}$, de Bordieu. Os significados são, portanto, públicos, assim como a cultura, dentro da qual os acontecimentos podem ser descritos, quando nos referimos ao sentido antropológico de cultura, temos consciência de que na antropologia não há apenas um conceito de cultura e tampouco uma abordagem única ou exata que fundamenta.

Para o Ministério do Turismo $(2010)^{3}$, cultura é entendida como a totalidade ou o conjunto da produção, de todo o fazer humano de uma sociedade, suas formas de expressões e modos de vida. A abrangência de seus significados se reflete na grande variedade de conceitos de cultura que são atualmente encontrados sobre ela. Há que se considerar, entretanto, que, a cultura de um povo ou de um grupo étnico específico é invocada a partir do sujeito que elabora um "discurso sobre si”, no qual está assume um valor positivo.

Portanto, não se deve esquecer que a reivindicação desse tipo de pertencimento passa pelos crivos da classe social, do nível de instrução, do gênero, da localidade de onde

\footnotetext{
${ }^{2}$ Utilizo aqui o conceito de habitus como o proposto por Bourdieu (apud ORTIZ, 1983, p. 65), ou seja como: “[...] um sistema de disposições duráveis e transponíveis que, integrando todas as experiências passadas, funciona a cada momento como uma matriz de percepções, de apreciações e ações - e torna possível a realização de tarefas infinitamente diferenciadas, graças as transferências analógicas de esquemas[...]".(Grifo meu)

${ }^{3}$ BRASIL. Ministério do Turismo. Segmentação do Turismo e o Mercado. $1^{\text {a }}$ Edição. Brasília, 2010.
} 
provem o descendente (se rural ou urbana), entre outros. A identidade étnica, dessa forma, permite que o indivíduo elabore uma discursividade sobre si, em que os elementos afetivos e simbólicos possuem um peso bastante forte. Elementos que são retirados do mundo dos antepassados, que passam a ser tratados como algo "sagrado", portadores de uma força significativa extremamente forte, e, neste sentido, o passado adquire sentido na medida em que é compartilhado no presente e utilizado como um modelo para o agir e identificar-se perante si e o seu grupo.

Com efeito, nossa sociedade formulou conceitos restritivos e deformantes de cultura, de valores culturais, de bens culturais, que se projetam também num certo tipo específico de "uso", restritivo e gerador de deformidades, ainda que apresentado como nobilitante, mas, na realidade, desqualificador de outros usos e funções.

\subsection{Bens Culturais e Patrimoniais para o Consumo Turístico}

Desta forma, ao se propor a alocação de Bens Culturais e de Patrimônio Histórico para o consumo turístico, buscamos em Barreto (2000, p. 33) que diz que, por meio do Turismo, o Patrimônio Cultural e Histórico pode ser valorizado e melhor preservado, pois:

(...) a revitalização de bairros inteiros para consumo cultural e turístico, sobretudo em áreas centrais ou portuárias de cidades, também tem sido uma forma de permitir a conservação das construções históricas existentes neles. A reutilização de prédios velhos e mesmo armazéns com finalidade cultural ou recreativa, para o lazer da população local ou dos turistas, e a aquisição dessas casas para moradia por intelectuais ou pessoas que procuram um contato com o passado, levam a uma valorização do local.

Parte-se do princípio que o Turismo é um dos meios mais dinâmicos na promoção da economia de um país, promovendo o crescimento econômico e social das mais diversas regiões e possibilitando, assim, a expansão do mercado de trabalho, gerando empregos e propiciando uma distribuição de renda mais justa.

No Brasil, segundo o IBGE (2013) ${ }^{4}$, o turismo impacta 52 segmentos diferentes da economia, empregando, em sua cadeia, desde a mão-de-obra mais qualificada, em áreas que se utilizam desde alta tecnologia (transportes e comunicação) até as de menor qualificação, tanto no emprego formal quanto no informal.

${ }^{4}$ IBGE - Instituto Brasileiro de Geografia Estatística. www.ibge.gov.br. Acessado em julho de 2018. 
Entre as vantagens do turismo como fonte geradora de empregos destaca-se a facilidade com que promoções e novos investimentos geram empregos, sem esquecer que tem a peculiaridade de gerar vagas em áreas com desemprego estrutural, como centros de cidades e áreas rurais.

Figura 01 - Interfaces do Patrimônio Cultural e Turismo

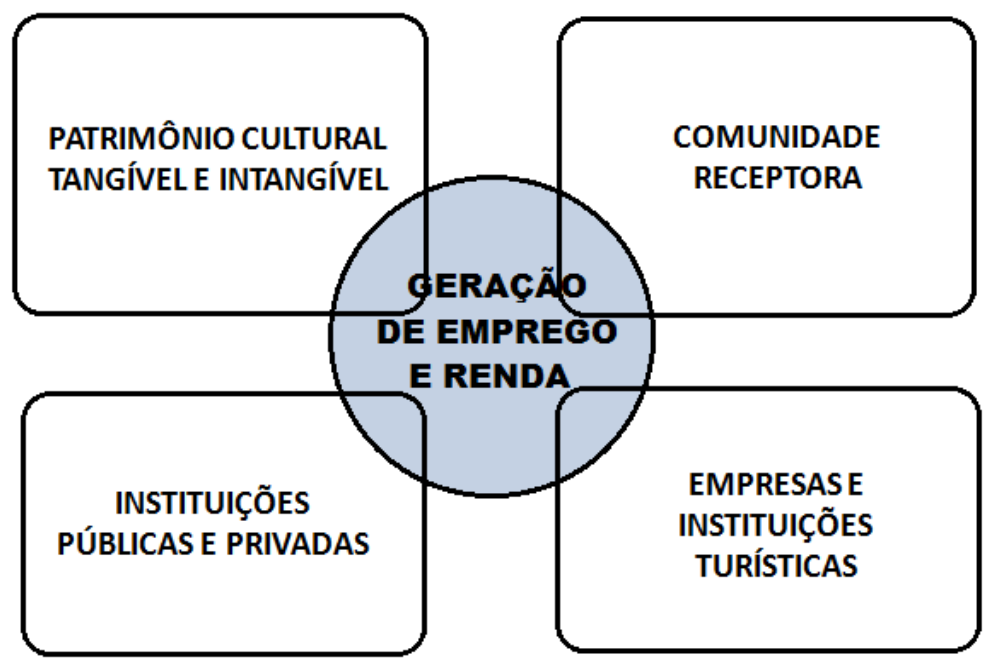

Fonte: Elaborado pelo autor, 2018

\section{OS NOVOS CENÁRIOS NO MUNDO DO TRABALHO E DO TURISMO}

Com o inexorável declínio do modelo industrial fordista, notadamente no mundo ocidental, criaram-se novos cenários onde se expressam as condições em que vive atualmente o turismo ${ }^{5}$, como: a reconversão das áreas degradadas - geralmente antigas áreas industriais ou parques fabris diversos - para fins turísticos; a busca novas estratégias de reconversão dos destinos turísticos consolidados; novos espaços turísticos de hiper-realidade ${ }^{6}$ e a crescente procura de estratégias turísticas de sustentabilidade, entre outros.

\footnotetext{
${ }^{5} \mathrm{O}$ turismo fordista tinha por base uma especialização setorial, a partir de poucos recursos naturais (praia ou montanha), numa oferta caracterizada pela homogeneização. O destinatário é visto como uma massa uniforme, esquecendo-se da singularidade da procura e das novas exigências. Outra característica é a contradição que se verifica entre uma oferta rígida e homogénea e uma procura em mudança e diferenciada. Este modelo turístico teve uma rápida consolidação por se basear no avanço tecnológico dos transportes e das comunicações e teve como objetivo estrutural a maximização do número de visitantes.

6 "Escapamos do mundo fordista para o mundo da fragmentação espacial da produção, materializado na interiorização e no deslocamento. A indústria de alta tecnologia substituiu as fábricas do século XX. Estamos na era da hiper-realidade, das empresas hiper-reais, como as da internet, que operam para além da materialidade do produto. O trabalho deixou de ser uma atividade para tornar-se uma operação" (BAUDRILLARD apud THIRYCHERQUES, 2010).
} 
A partir deste enquadramento, em que se desenham novos modelos da teoria e prática turística, emerge a necessidade de se proceder a uma reflexão pertinente e aprofundada, já que o turismo atual se redefine em moldes que ultrapassam as estratégias tradicionais.

Neste sentido é que se encontra a preocupação deste trabalho, pois a redescoberta do Patrimônio, em suas diversas manifestações, introduz no turismo novos espaços e realidades, como zonas industriais reconvertidas ou áreas abandonadas, seja pelo aproveitamento destes espaços desocupados, causados pelo fim do seu uso ou, num sentido por vezes definido como pós-moderno" ${ }^{7}$, transformar estes locais em espaços de memória ${ }^{8}$, introduzindo estes espaços de produção na lógica turística.

Um olhar emprestado da Antropologia sobre as questões aqui levantadas demonstra que essa disciplina pode apresentar caminhos e conceitos pertinentes no redimensionamento das estratégias relativas ao turismo, em se tratando de assuntos como os da Cultura, do Patrimônio e do Desenvolvimento Sustentado.

Os conceitos de patrimônio, autenticidade e identidade, emergentes nos modelos recentes da indústria turística devem sujeitar-se a uma abordagem antropológica analítica, pois a compreensão da motivação da procura é um fator chave da atividade da oferta turística porquanto a mesma subentende a percepção sobre as necessidades e desejos de consumo por parte da procura. Nas ciências sociais, associa-se o termo "motivação" a uma situação onde alguém está disposto a despender um esforço particular, tendo em vista a concretização de um determinado objetivo.

7 Segundo Jair Ferreira dos Santos (1994), o conceito pós-moderno foi empregado pelo historiador A. Toynbee em 1947 e aplicado por sociólogos norte-americanos para explicar as mudanças sociais da época, que denominavam como uma era pós-industrialização, mobilizada pelo consumo e pela informação em que a maior parte da força de trabalho estaria manipulando signos nos setores de serviços e técnico-científicos. De acordo com este autor, o ambiente pós-moderno: "significa basicamente isso: entre nós e o mundo estão os meios tecnológicos de comunicação, ou seja, de simulação. ... codificar e manipular o conhecimento e a informação na lógica 0/1 é vital para as sociedades pós-industriais, também chamadas sociedades programadas, onde cada serviço - banco, biblioteca, turismo - tem uma tela e um teclado com dígitos para você operar". (Santos, 1994, p. 13).

${ }^{8}$ Nesse sentido, pegamos emprestado o conceito de Pierre Nora sobre "Lugares de Memória" que reflete que estes locais se fazem pela experiência, pelos restos, resíduos daqueles que vivem o lugar e pela preocupação em perpetuar uma memória que é viva, mas crê-se no seu desaparecimento, daí a necessidade de um espaço que reviva essa memória, bem exemplificada pela a assertiva de que: "Os lugares da memória são, antes de tudo, restos. A forma extrema onde subsiste uma consciência comemorativa numa história que a chama, porque ela a ignora. É a desritualização de nosso mundo que faz aparecer a noção. O que secreta, veste, estabelece, constrói, decreta, mantém pelo artifício e pela vontade uma coletividade fundamentalmente envolvida em sua transformação e sua renovação. (...) os lugares de memória nascem e vivem do sentimento que não há memória espontânea, que é preciso criar arquivos, que é preciso manter aniversários, organizar celebrações, pronunciar elogios fúnebres, notariar atas, porque essas operações não são naturais". (NORA, 1993, p. 12). 
Um trabalho referencial pode ser encontrado em McIntosh (1999) que realçou a natureza subjetiva e emocional das experiências de contato com o patrimônio e os consequentes processos emotivos e cognitivos que produzem benefícios psicológicos únicos para os visitantes.

\subsection{Conceitos e Relações Patrimoniais}

O conceito de patrimônio inclui não apenas o conteúdo a que se refere, mas também as relações sociais e culturais que lhes são inerentes. Deve-se ressalvar que a herança patrimonial tem uma utilidade que vai para além do mero ato de guardar ou conservar. Ela é algo que enriquece as comunidades, porque lhes dá sentido, identifica-as com a sua memória, fazendo com que se transforme num capital, a que podem recorrer sempre que é preciso investir na consciência de si mesmas e na transformação do mundo onde age. A promoção da cultura integrada na vida sócio-econômica de uma cidade ou região constitui um elemento de inegável atração para o turismo, proporcionando alternativas interessantes aos visitantes. Contudo Pires et al $(2009)^{9}$ destacam que:

\footnotetext{
Por outro lado, a atividade turística nas comunidades locais e a geração de produtos e serviços para os visitantes, determinam transformações em suas estruturas nos âmbitos econômico, sociocultural e ambiental (GOELDNER et al, 2002), onde os impactos decorrentes e seus desdobramentos positivos e negativos nas localidades e regiões afetadas por esta atividade, se apresentam como matéria de investigação para a academia.
}

\section{CONSIDERAÇÕES FINAIS}

Por isso, entende-se que ao se criar um produto novo ou a se preservar um produto de turismo cultural, fomenta-se um ambiente cultural, promove-se a conservação dos bens culturais e do patrimônio histórico e a fidelização de um turismo de qualidade, promovendo, por fim, uma utilização e o desenvolvimento sustentado destes recursos, pois, não obstante as correntes filosóficas que se debruçaram sobre o turismo contemporâneo e do chamado pósmodernismo, com o advento de novos paradigmas e modelos turísticos, a ECO 92, no Rio de

\footnotetext{
${ }^{9}$ PIRES, Paulo dos Santos; ANJOS, Francisco A.; OLIVEIRA, Josildete Pereira de. SILVA, Yolanda Flores e. Estruturação de matriz de impactos do turismo: o caso do agroturismo no município de Santa Rosa de Lima/SC. Revista Brasileira de Pesquisa em Turismo v. 3, n. 1, p. 68-89, abril 2009.
} 
Janeiro, marcou uma nova etapa na abordagem do setor ao definir os princípios do um desenvolvimento sustentável como estratégia de ação futura.

A capacidade da atividade turística de gerar empregos e renda em comunidades distintas, sejam pequenas ou grandes aglomerados urbanos, com base no seu Patrimônio Cultural, seja tangível (edificado, gastronomia etc.) ou Intangível (Idioma, Folclore, Usos e Costumes etc) é uma realidade indiscutível e mais exemplos seriam redundantes nesse momento. Contudo, pode-se ressaltar que o Patrimônio Cultural de um grupo humano não se constituiu naturalmente em um produto para o consumo turístico, pois a degradação deste pode causar diversas fraturas nos processos identitários e de reconhecimento de heranças culturais específicas.

Não obstante, o planejamento adequado da oferta turística com base no patrimônio cultural pode ser um fator que impacta inexoravelmente uma comunidade, mas entende-se que assim pode-se gerar, nesta mesma comunidade, uma capacidade de responder às necessidades do presente (emprego, renda, preservação) sem comprometer as necessidades das gerações futuras; um processo de mudança que tem em conta a exploração dos recursos, a orientação dos benefícios, a aplicação das técnicas, a evolução das instituições, com o fim de reforçar o potencial socioeconômico do legado cultural, apto para responder às necessidades e aspirações distintas.

\section{REFERENCIA}

BARRETO, Margarita. Turismo e Legado Cultural. São Paulo: Papirus, 2000

BENI, Mário Carlos. Análise estrutural do turismo. 10 ed. (2004) e $13^{\text {a }}$ ed. (2008). São

Paulo: Senac.

BRASIL. Ministério do Esporte e Turismo. EMBRATUR - Instituto Brasileiro de Turismo. Anuário Estatistico 2018 - Turismo no Brasil. Disponível em:

<embratur.gov.br/anuário_2018/CNtur.php>. Acesso em junho de 2018. 2010. . Ministério do Turismo. Segmentação do Turismo e o Mercado. $1^{\text {a }}$ Edição. Brasília,

BRUSADIN, Leandro Benedini; SILVA, Rafael Henrique T. da. O Uso Turístico do Patrimônio Cultural em Ouro Preto. In: CULTUR (Revista de Cultura e Turismo), ano 06 - n $^{\circ}$ 01-Fev/2012. Disponível em:http://www.uesc.br/revistas/culturaeturismo/ano6edicao1/artigo_4.pdf

Disponível em: http://www.tandfonline.com/doi/abs/10.1300/J073v08n01_03 
GEERTZ, Clifford. A Interpretação das Culturas. Rio de Janeiro: LTC, 1989.

IBGE, Instituto Brasileiro de Geografia Estatística. www.ibge.gov.br, 2015.

MCINTOSH, Alison J. Into the Tourist's Mind: Understanding the Value of the Heritage Experience. Journal of Travel \& Tourism Marketing. pp. 41-64. Volume 8, Issue 1, 1999.

NORA, Pierre. Entre Memória e História: a problemática dos lugares. In: Projeto História. São Paulo: PUC, nº 10, PP. 07-28, dezembro de 1993.

ORTIZ, Renato. (Org). Sociologia. São Paulo: Ática, 1983.

PIRES, Paulo dos Santos; ANJOS, Francisco A.; OLIVEIRA, Josildete Pereira de. SILVA, Yolanda Flores e. Estruturação de matriz de impactos do turismo: o caso do agroturismo no município de Santa Rosa de Lima/SC. Revista Brasileira de Pesquisa em Turismo v. 3, n. 1, p. 68-89, abril 2009.

SANTOS, Jair Ferreira dos. O que é pós-moderno. 13. ed. São Paulo: Brasiliense, 1994.

THIRY-CHERQUES, Hermano Roberto. Baudrillard: trabalho e hiper-realidade. RAE electron. vol.9 no.1 São Paulo Jan./June 2010, disponível em http://dx.doi.org/10.1590/S1676-56482010000100008, acesso em julho de 2018.

WORLD TRAVEL \& TOURISM COUNCIL. Viagens \& Turismo: Impacto Econômico. Brasil. WTTC, 2015. Disponível em: http://www.wttc.org/stradev/.asp. 